\title{
Collapse of an arctic bird community resulting from ungulate- induced loss of erect shrubs
}

\author{
Rolf A. Ims and John-André Henden \\ Department of Arctic and Marine Biology, University of Troms $\varnothing$, NO-9037 Troms $\varnothing$, Norway
}

Short title: Collapse of an arctic bird community

*Corresponding Author: John-Andre Henden (john-andre.henden@ uit.no)

Submitted as a Short communication to Biological Conservation

Word count: 2721 


\begin{abstract}
Rapid, but contrasting, changes in the extent of erect thicket-forming shrubs is presently seen in the Arctic, either resulting from a warmer climate (increasing extent) or intensified herbivory (decreasing extent). We investigated the impact of loss of willow shrubs on a bird community in arctic riparian sediment plains in northern Norway subject to varying intensities of reindeer browsing. In riparian habitats where willow thickets had been lost, bird species richness was more than halved compared to habitats where some patches of thickets were still present. As could be expected species previously suggested to use erect woody vegetation as nesting places and/or foraging habitats were most consistently impacted. However, even some open ground habitat specialists appeared to be negatively impacted, possibly due to loss of spatial spill-over effects of insects from willow thickets. To preserve low-arctic avian biodiversity in a warming climate, management should strive to identify levels of ungulate browsing that strike the balance between shrub-encroached and shrub-denuded arctic tundra.
\end{abstract}

Key-words: Arctic tundra, Climate warming, habitat occupancy, intense browsing, species richness 


\section{Introduction}

Erect shrubs are functionally important but labile components of many ecosystems because such woody plants respond rapidly to both abiotic and biotic environmental change (van Auken et al., 2000; Eldrich et al., 2011). In the Arctic thicket-forming shrubs of Alnus, Betula and Salix now rapidly encroach on open tundra under climate warming in some regions (Sturm et al., 2001, 2005; Tape et al., 2006; Forbes et al., 2010), while intense browsing by ungulates reduces their extent in yet other regions (den Herder et al., 2006, 2008; Ims et al., 2007; Olofsson et al., 2009; Forbes et al., 2009). While the effects of these changes on biophysical processes have received profound attention (e.g. Sturm et al., 2005; Chapin et al., 2005), the consequences for biodiversity have been less focused. Obviously, species tightly linked to thicket-forming shrubs can be expected to respond strongly to such habitat changes. Similarly, tundra species affiliated with short-statured plant growth forms (which constitutes the alternative vegetation to tall thicket-forming shrubs) are also expected to respond, albeit opposite of thicket-affiliated species. For yet other species the strength and sign of the response may be conditional on several indirect effects that may be exerted when such major changes in an ecosystem takes place. Here we examine the effects of loss of willow shrubs resulting from intense ungulate browsing on an arctic bird community.

\section{Methods}

\subsection{Study system and design}

The study was carried out in the regions of Varanger peninsula and Laksefjord tundra $\left(70-71^{\circ}\right.$ $\mathrm{N}$ ) in northern Norway. In each region we located 10-11 bird census plots in riparian sediment plains in a matched design with 5-6 plots with and without willow thickets, respectively. Habitats with willow thickets (Fig. 1A) had patches of approximately $80-240 \mathrm{~cm}$ tall shrubs that formed closed canopies surrounded by meadows with short-statured vegetation of non- 
woody plants (Henden et al., 2011a). Habitats without thickets either had tall willows (2 plots) so severely thinned by reindeer browsing that they no longer formed closed canopies (Fig. 1B) or (9 plots) only contained scattered small willow ramets that did not exceed in height the non-woody meadow vegetation (Fig. 1C). A recent exclosure experiment has shown that such willow ramets in riparian meadows in this study region are severely suppressed due to intense browsing (Ravolainen et al., 2011). The level of browsing even in the riparian habitats with willow thickets was high enough to cause substantial fragmentation of the willow thickets (Fig. 1A). The different intensities of browsing reindeer between habitats with and without thickets in Laksefjord were due to fencing separating summer (high browsing intensity) from autumn-spring pastures (low browsing intensity). In Varanger the two types of habitats were found in separate valleys subject to different intensities of traditional reindeer habitat use in summer (Vorren, 1962). The 10 plots with willow thickets was a sub-set of a larger sample of plots selected to investigate the effect of willow thicket fragmentation on various taxa (Henden et al., 2011a, b). The subset was made to geographically match plots with and without thickets as much as possible. The maximum distance between plots with and without willow thickets was $5.3 \mathrm{~km}$ in Varanger and $3.3 \mathrm{~km}$ in Laksefjord. The range of altitudes (above sea-level) of plots with and without thickets was also similar (Varanger: 151-171m with thickets and 165-184m without, Laksefjord: 219-299m with thickets and 233-286m without).

\subsection{Bird census method}

Bird censuses in plots with thickets were conducted by an observer standing in the meadow at the edge of the willow thickets, which aligned streams and rivers cutting through the plains. In plots without thickets the observer was standing at a similar distance from a waterway. Censuses were made by point sampling (Hausner et al., 2002) with detection radius set to $100 \mathrm{~m}$ (i.e. plot size 3.14 ha). Five replicate censuses in each of the 21 plots were made by one 
of us (RAI) during good weather in early July over the years 2010 and 2011. The recording period for each replicate was 15 minutes. Birds were recorded in the evening from 19.00 23.00 and in the morning from $02.00-10.00$ as birds are most vocal at this time at these latitudes (Hausner et al., 2002). Care was still taken to get matching recording times between plots with and without thickets.

Published knowledge of habitat-species relations for low arctic tundra bird communities is mainly found in qualitative natural history accounts. We used two such sources relevant for the focal geographic region (Haftorn, 1971; Ratcliffe, 2005) to tentatively categorize the observed bird species into two main groups based on habitat use; i.e. species expected to have a specific affiliation (foraging, nesting) with erect woody vegetation (e.g. tall willow shrubs) or known to be affiliated with open tundra.

\subsection{Estimation of habitat occupancy and species richness}

We employed a Bayesian approach for estimation of species-specific occupancy and community species richness adopting a two-habitat hierarchical model (Zipkin et al., 2010). In this model true absence from non-detection is distinguished by specifically incorporating presence-absence and detection-nondetection, the latter depending on whether a species is actually present, as two distinct processes. We simulated the model using WinBUGS 1.4 (Spiegelhalter et al., 2003) and ran the model using two chains of 20.000 iterations after a burn-in of 10.000 and thinned the posterior chains by 2. Model convergence was assessed according to Rhat-statistic (Gelman and Hill, 2007).

\section{Results}

A cumulative number of 16 terrestrial bird species that was observed in the riparian habitats entered the estimation of species-specific habitat occupancy and community level species 
richness. While all species were observed in plots with willow thickets, only 9 were observed in plots without thickets. Published knowledge of habitat-species relations for low arctic tundra bird communities is mainly found in qualitative natural history accounts. Seven of the 16 observed species were a priori suggested to have a specific affiliation (foraging, nesting) with erect woody vegetation (Table 1), whereas the other 9 species were classified as being affiliated with open tundra.

The estimated habitat occupancies at the plot level were for most species lower when willow thickets were absent than when they were present (Table 1, Fig. 2). The impact of loss of thickets was most pronounced in species a priori suggested to use erect woody vegetation for foraging and/or nesting. However surprisingly, even some species known to prefer open tundra with short-statured vegetation had lower occupancy estimates in habitats without willow thickets (Table 1).

The estimated species richness within the 3.14 ha study plots decreased from $10.88[ \pm$ $0.45 \mathrm{SD}]$ in habitats with thickets to $4.98[ \pm 0.87 \mathrm{SD}]$ in habitats where willow thickets were missing. The distributions of plot-specific richness estimates for the two types of riparian habitats were distinctly non-overlapping (Fig. 2).

\section{Discussion}

The bird species assemblage in riparian arctic tundra habitats experienced such a substantial reduction in prevalence and species richness associated with loss of willow thickets that the impact of ungulate overbrowsing warrants to be termed "community level collapse". More than half of the species disappeared along with the willow thickets. Among those species found to be still present, most species experienced a lower occupancy. The negative impacts were, as could be expected, most pronounced in species suggested to depend on erect woody vegetation as nesting places and/or foraging habitats. For these (mainly passerine) species our 
study provide a quantitative verification of the qualitative descriptions that often prevails in natural history literature on birds from the arctic region (i.e. Ratcliffe, 2005).

For birds that are known to be affiliated with open habitats one could have expected that they would become facilitated by the loss of willow thickets. However, this expectation was not met as the response in such species was either neutral or negative. We suspect that the negative responses in these insectivorous birds result from halted spatial spillover of food resources from the rich fauna of insects dwelling in the willow thickets (den Herder et al., 2004) onto the surrounding open habitats. However, we cannot exclude that even changed composition of the non-woody components of the meadow vegetation resulting from intense reindeer grazing (Ravolainen et al., 2011) may have contributed to the lower habitat occupancy of bird species affiliated with open tundra.

\subsection{Conclusions}

Management for increased abundance of browsing ungulates has recently been proposed as a putative ecological engineering to counteract climate-induced shrub encroachment on open Arctic tundra (Post and Pedersen, 2008, Olofsson et al., 2009). This proposal is motivated by the expectation that large-scale shrub encroachment will cause positive feedbacks on global climate warming though biophysical processes (Chapin et al., 2005). However, this study reveals strong positive effects of willow thickets on avian biodiversity associated with low arctic tundra. Management should thus strive to identify levels of ungulate browsing that strike the balance between shrub-encroached and shrubdenuded arctic tundra in a warming climate.

\section{Acknowledgements}


The study received funding from the Research Council of Norway to the EcoFinn project and is an activity within Nordic Centre of Excellence - How to preserve the Tundra in a changing climate.

\section{Literature cited}

Chapin, F.S., Sturm, M., Serreze, M.C., McFadden, J.P., Key, J.R., Lloyd, A.H., McGuire, A.D., Rupp, T.S., Lynch, A.H., Schimel J.P., Beringer, J., Chapman, W.L., Epstein, H.E., Euskirchen, E.S., Hinzman, L.D., Jia, G., Ping, C.-L., Tape, K.D., Thompson, C.D.C., Walker D.A., Welker, J.M., 2005. Role of land-surface changes in Arctic summer warming. Science 310, 657-660.

den Herder, M., Virtanen, R., Roininen, H., 2004. Effects of reindeer browsing on tundra willow and its associated insect herbivores. Journal of Applied Ecology 41, 870-879.

den Herder, M., Virtanen, R., Roininen, H., 2008. Reindeer herbivory reduces willow growth and grouse forage in a forest-tundra ecotone. Basic \& Applied Ecology 9, 324-331.

Eldrich, D.J., Bowker, M.A., Maestre, F.T., Roger, E., Reynolds, J.F., Witfor, W.G., 2011. Impacts of shrub encroachment on ecosystem structure and functioning: towards a global synthesis. Ecology Letters 14, 709-722.

Forbes, B.C., Stammler, F., Kumpula, T., Meschtyb, N., Pajunen, A., Kaarlejarvi, E., 2009. High resilience in the Yamal-Nenets social-ecological system, West Siberian Arctic, Russia. Proceeding of the National Academy of Science USA 106, 22041-22048.

Forbes, B.C., Fauria, M.M., Zetterberg, P., 2010. Russian Arctic warming and 'greening' are closely tracked by Tundra shrub willows. Global Change Biology 16, 1542-1554.

Gelman, A., Hill, J., 2007. Data analysis using regression and multilevel/hierarchical models. Cambridge University Press, New York.

Haftorn, S., 1971. Norges fugler. Universitetsforlaget, Oslo. 
Hausner, V.H., Yoccoz, N.G., Strann, K.B., Ims, R.A., 2002. Changes in bird communities by planting non-native spruce in coastal birch forests of northern Norway. Ecoscience 9, $470-481$.

Henden, J.-A., Ims, R.A., Yoccoz, N.G., Sørensen, R., Killengreen, S.T., 2011a. Population dynamics of tundra voles in relation to configuration of willow thickets in southern arctic tundra. Polar Biology 34, 533-540.

Henden, J.-A., Ims, R.A., Yoccoz, N.G., Killengreen, S.T., 2011b. Declining willow ptarmigan populations: The role of habitat structure and community dynamics. Basic \& Applied Ecology 12, 413-422.

Ims, R.A., Yoccoz, N. G., Bråthen, K.A., Fauchald, P., Tveraa, T., Hausner, V., 2007. Can reindeer overabundance cause a trophic cascade? Ecosystems 10, 607-622.

Olofsson, J., Oksanen, L., Callaghan, T., Hulme, P.E., Oksanen, T., Suominen, O., 2009. Herbivores inhibit climate-driven shrub expansion on the tundra. Global Change Biology 15, 2681-2693.

Post, E., Pedersen, C., 2008. Opposing plant community responses to warming with and without herbivores. Proceedings of the National Academy Science USA 105, 1235312358.

Ratcliffe, D., 2005. Lapland - A natural history. T \& AD Poyser, London.

Ravolainen, V.T., Bråthen, K.A., Ims, R.A., Yoccoz, N.G., Henden, J.-A., Killengreen, S.T., 2011. Rapid, landscape scale responses in riparian tundra vegetation to exclusion of small and large mammalian herbivores. Basic \& Applied Ecology 12, 643-653.

Spiegelhalter, D.J., Thomas, A., Best, N.G., Lunn, D., 2003. WinBUGS Version 1.4 User Manual. MRC Biostatistics Unit, Cambridge.

Sturm, M., Racine, C., Tape, K., 2001. Climate change - Increasing shrub abundance in the Arctic. Nature 411, 546-547. 
Sturm, M., Schimel, J., Michaelson, G., Welker, J.M., Oberbauer, S.F., Liston, G.E., Fahnstock, J., Romanovsky, V.E., 2005. Winter biological processes could help to convert arctic tundra to shrublands. BioScience 55, 17-26.

Tape, K., Sturm, M., Racine, C., 2006. The evidence for shrub expansion in Northern Alaska and the Pan-Arctic. Global Change Biology 12, 686-702.

van Auken, O.W., 2000. Shrub invasions of North American semiarid grasslands. Annual Review of Ecology and Systematics 31, 197-215.

Vorren, Ø., 1962. Finnmarksamenes nomadisme II. Universitetsforlaget, Oslo.

Zipkin, E.F., Royle, J.A., Dawson, D.R., Bates, S., 2010. Multi-species occurrence models to evaluate the effects of conservation and management actions. Biological Conservation $143,479-484$. 
Table 1. Estimated species-specific occupancy (probability of occurrence) in riparian habitats with and without willow thickets. Species and estimates in bold denote that their standard deviation intervals do not overlap between the two habitat types. *: denotes species that were not observed in plots without thickets. The column "category" distinguishes the species based on natural history accounts on habitat use (Haftorn 1971, Ratcliffe 2005) where those denoted $\mathrm{N}$ use erect woody vegetation for nesting, $\mathrm{F}$ use erect woody vegetation as forage or foraging habitat and $\mathrm{O}$ use open ground habitats with short-statured vegetation.

\begin{tabular}{|c|c|c|c|}
\hline Species & Category & $\begin{array}{l}\text { With thickets } \\
\text { Occupancy [SD] }\end{array}$ & $\begin{array}{l}\text { Without thickets } \\
\text { Occupancy [SD] }\end{array}$ \\
\hline Brambling Fringilla montifringilla & NF & $0.64[0.26]$ & $0.09[0.14]^{*}$ \\
\hline Common Redpoll Carduelis flammea & NF & $0.92[0.08]$ & $0.28[0.19]$ \\
\hline Willow Ptarmigan Lagopus lagopus & $\mathbf{F}$ & $0.71[0.22]$ & $0.09[0.16]^{*}$ \\
\hline Willow Warbler Phylloscopus trochilus & $\mathbf{F}$ & $0.79[0.12]$ & $0.09[0.14]^{*}$ \\
\hline Bluethroat Luscinia svecica & $\mathbf{F}$ & $0.78[0.16]$ & $0.09[0.14]^{*}$ \\
\hline Redwing Turdus iliacus & $\mathbf{N}$ & $0.44[0.19]$ & $0.09[0.15]^{*}$ \\
\hline Fieldfare Turdus pilaris & $\mathbf{N}$ & $0.64[0.26]$ & $0.09[0.15]^{*}$ \\
\hline Long-tailed Skua Stercorarius longicaudus & $\mathrm{O}$ & $0.66[0.25]$ & $0.54[0.26]$ \\
\hline Rough-legged Buzzard Buteo lagopus & 0 & $0.37[0.32]$ & $0.40[0.21]$ \\
\hline Eurasian Golden Plover Pluvialis apricaria & 0 & $0.83[0.14]$ & $0.33[0.22]$ \\
\hline Meadow Pipit Anthus pratensis & $\mathrm{O}$ & $0.92[0.08]$ & $0.85[0.13]$ \\
\hline Red-throated Pipit Anthus cervinus & 0 & $0.43[0.24]$ & $0.40[0.26]$ \\
\hline Lapland Bunting Calcarius lapponicus & $\mathrm{O}$ & $0.54[0.15]$ & $0.25[0.17]$ \\
\hline White Wagtail Motacilla alba & 0 & $0.69[0.19]$ & $0.83[0.15]$ \\
\hline Northern Wheatear Oenanthe oenanthe & 0 & $0.54[0.30]$ & $0.09[0.15]^{*}$ \\
\hline Temminck's stint Calidris temminckii & $\mathrm{O}$ & $0.50[0.22]$ & $0.35[0.19]$ \\
\hline
\end{tabular}




\section{Figure legends}

Fig. 1. Examples of riparian habitats with different degrees of loss of willow shrubs included in the present study. A) Patches of willow thickets imbedded in a matrix of meadow vegetation. B) Willow shrubs being thinned by reindeer browsing to the extent that they do not form patches with closed canopies (i.e. thickets). C) All erect willows are missing and only small willow ramets (not seen on the photo) are found in the meadow vegetation. Plots in states B and C were in this study treated as habitats without willow thickets.

Fig. 2. Left: Distributions of the plot-specific species richness estimates in riparian habitats with and without willow thickets displayed by box plots. Right: Scatter plot of speciesspecific probabilities of occurrence (occupancy) in habitats with thickets vs. habitats without thickets. Dashed black line is the regression line based on the occupancy estimates whereas the solid grey line represents the expected relation based on same occupancy in the two habitats. The points denote the occupancy estimates for each of the 16 species observed. 
Fig. 1.

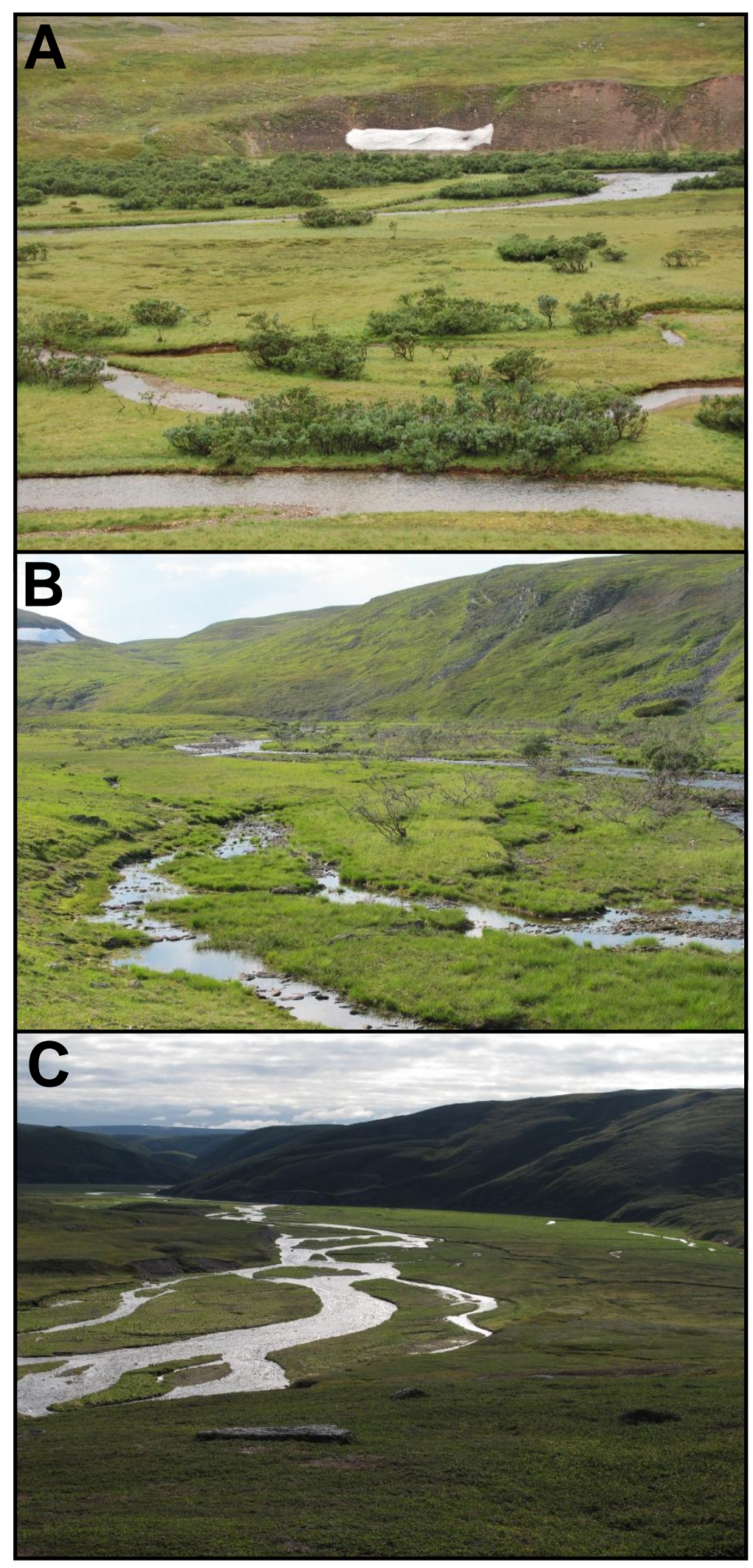


Fig. 2.
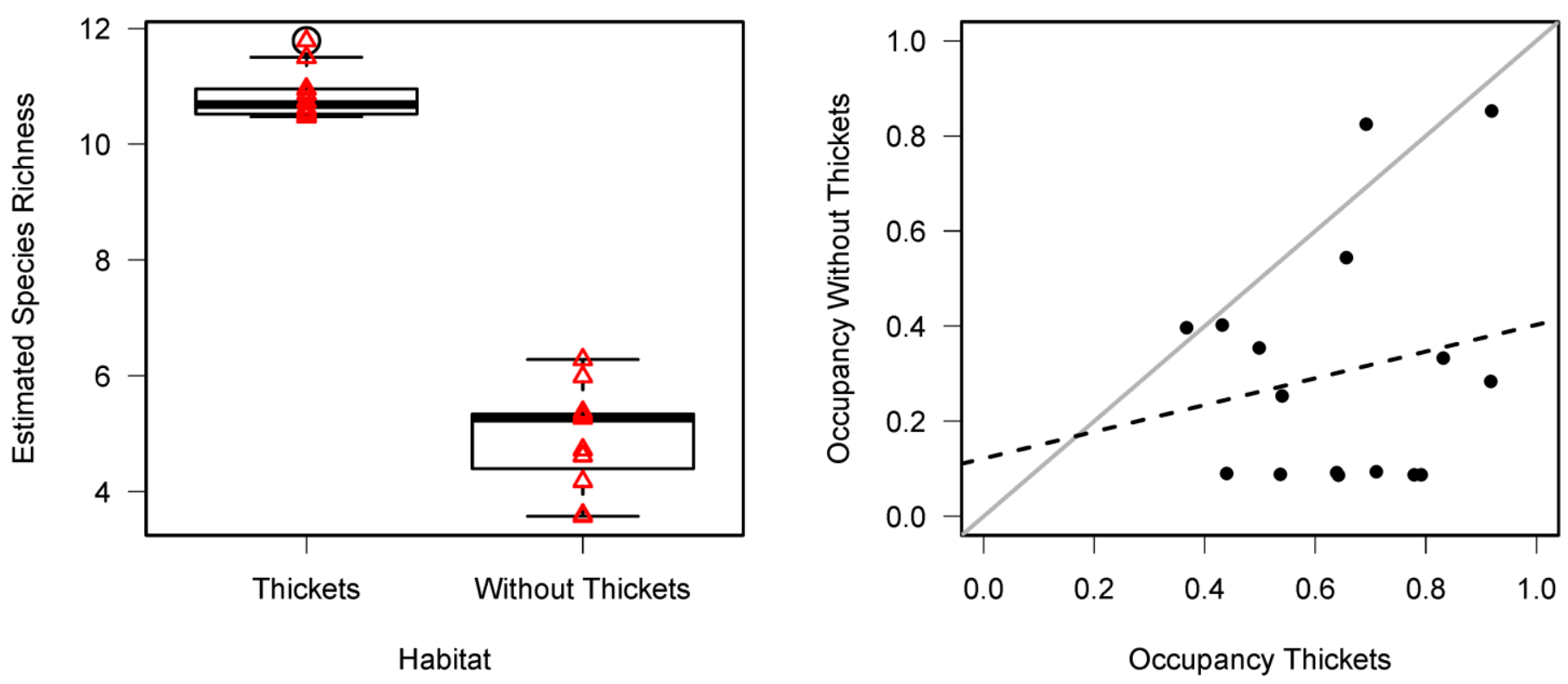

Habitat 